\title{
Masa abdominal palpable
}

\author{
F. Garnateo, A. Beguiristain, R. Jiménez, M. A. Medrano, I. Ruiz, J. M. Villar, I. Irureta, X. Arteaga \\ y M. Sota
}

Servicio de Cirugía General y Digestiva. Hospital Donostia. San Sebastián, Guipúzkoa

\section{CASO CLÍNICO}

Mujer de 83 años de edad que ingresa por cuadro de astenia, anorexia, dolor abdominal y vómitos. Paciente con antecedentes de colitis ulcerosa en tratamiento con salazopirina. Durante el ingreso presenta fiebre y persiste el dolor abdominal.

En TAC abdómino-pélvico (Fig. 1) se evidencia colección hidroaérea pélvica, parasigmoidea sospechosa de poder corresponder a un área volvulada de sigma o un absceso de origen diverticulítico. En colonoscopia, diverticulosis de sigma con zona rígida entre divertículos que ofrece resistencia a la progresión del endoscopio.

Debido a los hallazgos se instaura tratamiento antibiótico y TAC de control (Fig. 2) con punción si es oportuno. Al realizar este, se observa que dicha colección hidroaérea presenta en la actualidad un contenido exclusivamente aéreo.

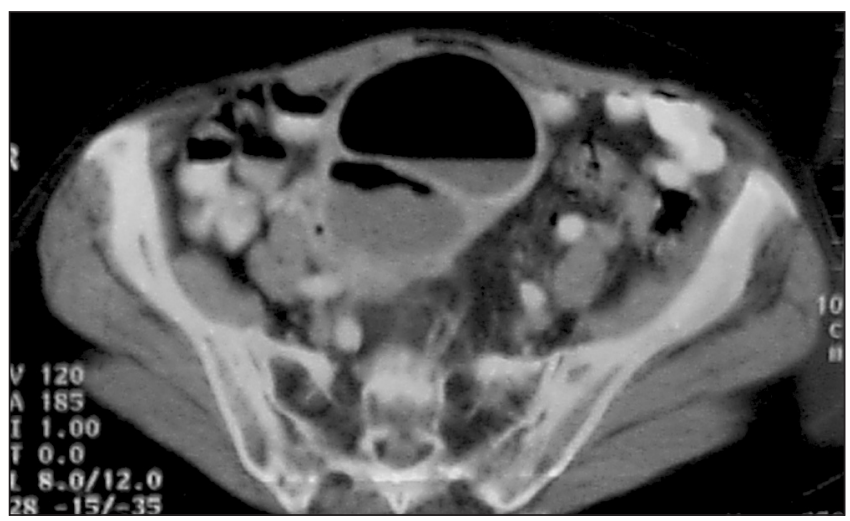

Fig. 1.

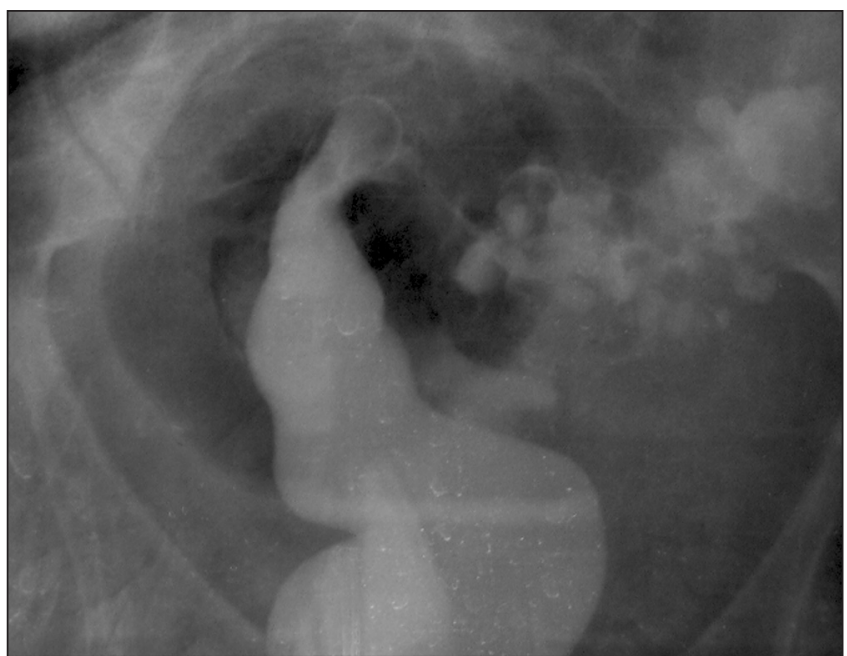

Fig. 3.

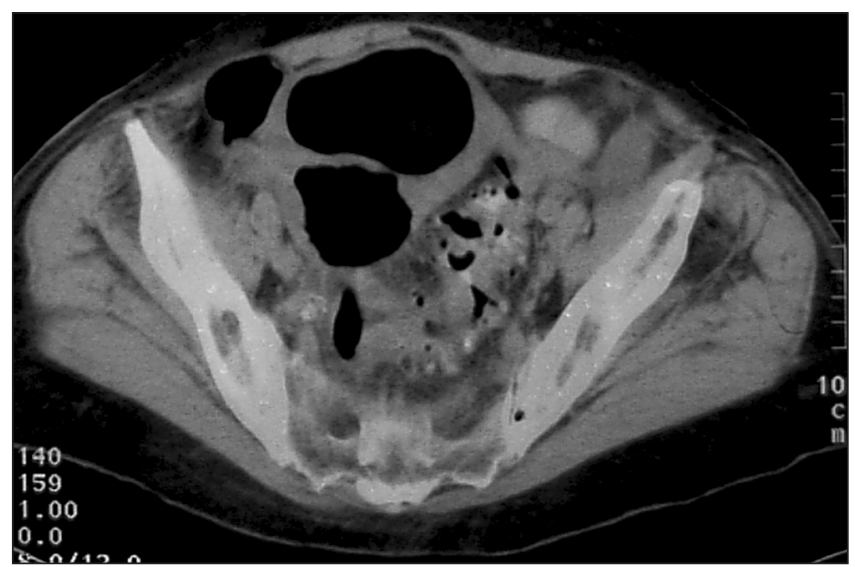

Fig. 2.

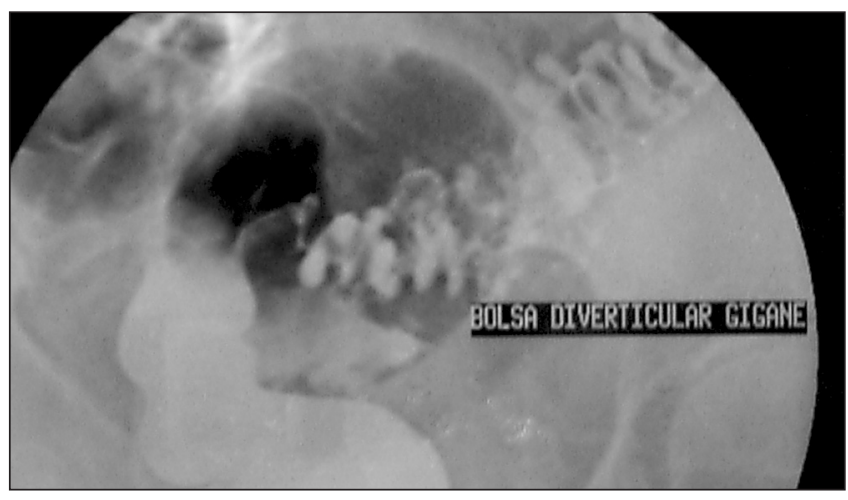

Fig. 4. 
Debido al resultado del último TAC se decide realizar enema opaco observandose divertículo gigante cólico en sigma con efecto valvular que se rellena parcialmente (Figs. 3 y 4 ).

Con estos hallazgos, se decide realizar intervención quirúrgica programada para tratamiento de dicha lesión. Los hallazgos quirúrgicos corresponden a un absceso paradiverticular como complicación de una diverticulitis perforada. Se practicó drenaje del absceso y resección anterior de sigma.

La evolución postoperatoria fue satisfactoria, y el informe anátomo-patológico confirmó dicho diagnóstico.

El divertículo gigante de colon es una rara complicación de la enfermedad diverticular de colon. Frecuentemente, son asintomáticos. El diagnóstico se puede realizar con Rx de abdomen, TAC o enema opaco, aunque puede ser difícil de realizar, a pesar de la utilización de dichas pruebas. El tratamiento de elección consiste en una resección segmentaria de colon con anastomosis primaria.

\section{BIBLIOGRAFÍA RECOMENDADA}

1. Steenvoorde P, Vogelaar FJ, Oskam J, Tollenaar RAEM. Giant colonic diverticula: Review of diagnostic and therapeutic options. Dig Surg 2004; 21: 1-6.

2. Naing T, Ray S, Loughran CF. Giant sigmoid diverticulum: A report of three cases. Clinical Radiology 1999; 54: 179-81.

3. Timothy J, Custer MD, David V, Blevins MD, Thomas M, Vara MD. Giant colonic diverticulum: a rare manifestation of common disease. J Gastrointest Surgery $1999 ; 3: 543-8$ 